\title{
Familiespørsmål i hjerte-karundersøkelsene
}

\author{
Knut Westlund
}

Statens helseundersøkelser

Korrespondanse til: Aage Tverdal, Forskningsavdelingen, Statens helseundersøkelser, Postboks 8155 Dep, 0033 Oslo

\section{INNLEDNING}

Statens helseundersøkelser har i mange år hatt et spørsmål på sitt hovedskjema: "Har en eller flere av foreldre eller søsken hatt hjerteinfarkt (sår på hjertet) eller angina pectoris (hjertekrampe)?". Svaralternativene er Ja, Nei og Vet ikke. Dette primitive spørsmål har vist seg både å ha sammenheng med serumkolesterol og triglyserider $(1,2)$ og med insidens og dødelighet av hjerteinfarkt etter justering for vanlige risikofaktorer $(3,4)$. Svaret Vet ikke ligger i de fleste sammenhenger nærmere Ja enn Nei.

Formålet med denne artikkel er å gi noen eksempler på enkel analytisk bruk av opplysninger om sykdom hos foreldre eller søsken i de to første omganger av 40-åringsundersøkelsene i Østfold og Aust-Agder. Dernest gis en oversikt over anvendte metoder og sykdommer som det er spurt om i forskjellige norske befolkningsundersøkelser.

\section{MATERIALET I ØSTFOLD OG AUST-AGDER}

De to første omganger av hjerte-karundersøkelsene av personer i alder 40-42 år i Østfold og Aust-Agder foregikk i årene 1985-1989. Det vanlige hovedskjema på innkallingsbrevets bakside ble brukt, med spørsmål om en eller flere av foreldre eller søsken har hatt hjerteinfarkt eller angina pectoris med svaralternativene Ja, Nei og Vet ikke. Dessuten ble det ved undersøkelsen delt ut et ekstra spørreskjema som ble returnert pr. post. Dette skjema inneholdt spørsmål om følgende tilstander hos en eller flere av foreldre eller søsken: Høyt blodtrykk, sukkersyke, coeliaci og psoriasis, alle med svaralternativene Ja og Nei. Et utvalg fra første omgang - alle som fikk utskrevet meldekort til primærlegen på grunn av risiko samt tilfeldige $10 \% \mathrm{av}$ de øvrige inviterte - ble invitert til gjenundersøkelse i andre omgang tre år senere, og vel 1700 møtte begge ganger. Detaljer om undersøkelsene, med kopi av de anvendte skjemaer finnes i (5). Denne artikkelen gir data fra de to fylker samlet.

\section{NOEN RESULTATER FRA ØSTFOLD OG AUST-AGDER}

Tabell 1 viser kappa (koeffisient for reliabilitet) for sykdomssvar fra personer som ble undersøkt to ganger med 3 års mellomrom. Ca. 1130 menn og 630 kvinner svarte begge ganger på spørsmålene på hovedskjemaet. Derimot var antallene vesentlig lavere for svar begge ganger på tilleggsskjemaets spørsmål, lavest for sukkersyke hos foreldre og søsken (476 menn og 262 kvinner).

Tabell 1. Personer undersøkt to ganger. Kappa for svar om egen sykdom og om sykdom hos foreldre eller søsken.

\begin{tabular}{lcc}
\hline & MENN & KVINNER \\
\hline & \multicolumn{2}{c}{ Egen sykdom } \\
Hjerteinfarkt &, 77 &, 57 \\
Angina pectoris &, 51 &, 55 \\
Behandles høyt blodtrykk &, 54 &, 63 \\
Sukkersyke &, 77 &, 75 \\
Psoriasis &, 74 &, 84 \\
Coeliaci & 1,00 & Ingen Ja-svar \\
& & \\
& Sykdom hos foreldre eller søsken \\
Hjerteinfarkt eller & & \\
angina pectoris &, 73 &, 72 \\
Høyt blodtrykk &, 68 &, 75 \\
Sukkersyke &, 81 &, 74 \\
Psoriasis &, 73 &, 83 \\
Coeliaci &, 50 &, 67 \\
\hline
\end{tabular}

Kappa er av samme størrelsesorden for egen sykdom og for sykdom hos foreldre eller søsken. Endring mellom omgangene kan skyldes en reell endring, dvs. ny sykdom i løpet av de 3 år eller at en diagnose er blitt revidert. I de fleste tilfelle vil imidlertid en endring fra Ja til Nei i familiespørsmålene være resultat av usikkerhet $\mathrm{i}$ den ene eller begge omganger.

For alle som møtte i alder 40-42 og besvarte de aktuelle spørsmål, kan relativ prevalens beregnes for personer med og uten kjent tilstand blant foreldre eller søsken (tabell 2). For alle tilstander er relativ prevalens klart over 1. Det er imidlertid usikkert i hvilken grad dette gjenspeiler reell relativ risiko. Mulighetene for bias er mange, både ved at egen sykdom fører til interesse for lignende sykdom i familien, ved at sykdom i familien fører til at man selv blir undersøkt, eller rett og slett ved at familiemedlemmer benytter samme lege. Trolig vil bias lettest gjøre seg gjeldende 
Tabell 2. Egen sykdom/tilstand relatert til sykdom/tilstand hos foreldre eller søsken. Alder 40-42 år.

\begin{tabular}{|c|c|c|c|c|c|c|c|c|}
\hline \multirow[b]{2}{*}{$\begin{array}{l}\text { Tilstand } \\
\text { foreldre/søsken }\end{array}$} & \multicolumn{4}{|c|}{ MENN } & \multicolumn{4}{|c|}{ KVINNER } \\
\hline & Svar i alt & $\begin{array}{l}\text { "Ja" egen } \\
\text { tilstand }\end{array}$ & $\begin{array}{c}\text { Prevalens } \\
\% \\
\end{array}$ & $\begin{array}{l}\text { Relativ } \\
\text { prevalens }\end{array}$ & Svar i alt & $\begin{array}{l}\text { "Ja" egen } \\
\text { tilstand }\end{array}$ & $\begin{array}{c}\text { Prevalens } \\
\% \\
\end{array}$ & $\begin{array}{c}\text { Relativ } \\
\text { prevalens }\end{array}$ \\
\hline & \multicolumn{8}{|c|}{ Selv hjerteinfarkt } \\
\hline $\mathrm{Ja}$ & 4086 & 43 & 1,05 & & 4603 & 4 & 0,087 & \\
\hline $\mathrm{Nei}$ & 6868 & 10 & 0,15 & 7,0 & 6974 & 2 & 0,029 & 3,0 \\
\hline \multirow[t]{2}{*}{ Vet ikke } & 526 & 4 & 0,80 & & 464 & - & - & \\
\hline & \multicolumn{8}{|c|}{ Selv sukkersyke } \\
\hline $\mathrm{Ja}$ & 828 & 24 & 2,90 & & 975 & 21 & 2,15 & \\
\hline \multirow[t]{2}{*}{ Nei } & 6105 & 64 & 1,05 & 2,8 & 6781 & 35 & 0,52 & 4,1 \\
\hline & \multicolumn{8}{|c|}{ Selv på blodtrykksbehandling } \\
\hline $\mathrm{Ja}$ & 2440 & 184 & 7,54 & & 3501 & 197 & 5,63 & \\
\hline \multirow[t]{2}{*}{ Nei } & 5389 & 98 & 1,82 & 4,1 & 5211 & 80 & 1,54 & 3,7 \\
\hline & \multicolumn{8}{|c|}{ Selv psoriasis } \\
\hline $\mathrm{Ja}$ & 570 & 153 & 26,84 & & 784 & 182 & 23,21 & \\
\hline \multirow[t]{2}{*}{ Nei } & 7046 & 238 & 3,38 & 7,9 & 7526 & 161 & 2,14 & 10,8 \\
\hline & \multicolumn{8}{|c|}{ Selv coeliaci } \\
\hline $\mathrm{Ja}$ & 24 & 3 & 12,50 & & 36 & - & - & \\
\hline Nei & 7217 & 8 & 0,10 & & 7880 & 16 & 0,20 & \\
\hline
\end{tabular}

ved høyt blodtrykk, muligens minst ved psoriasis som har høyest ratio i begge kjønn.

Familiespørsmålene slår ut også i multivariable tverrsnittsanalyser der blodtrykk og blodlipider er avhengige variable. Spesielt gjelder dette for kjent høyt blodtrykk hos foreldre/søsken som prediktor for blodtrykk, noe mer for diastolisk enn systolisk blodtrykk. Infarkt/ angina hos foreldre/søsken bidrar mindre til prediksjon av serumkolesterol og triglyserider, men dette kan ha sammenheng med at flere miljøvariable bidrar til prediksjon av blodlipider enn av blodtrykk (5).

Man kunne tenke seg at kjennskap til sykdom i familien ville føre til økt interesse, ikke bare for egen sykdom men også for egen risiko og forebyggende tiltak. Tabellene 3-5 gir data for personer som svarte "Nei" på om de selv hadde en tilstand, men "Ja" på det tilsvarende familespørsmål. I tabellene er "Infarktrisk" den index som brukes av Statens helseundersøkelser som en tilnærming til risikoen for å dø av hjerteinfarkt i de nærmeste år. Indexen bygger på kjønn, serumkolesterol, systolisk blodtrykk, antall sigaretter per dag og hjerteinfarkt eller angina pectoris hos foreldre eller søsken. Detaljer finnes i (6). Den høye infarktrisk i tabell 3 for dem som svarte Ja på familiespørsmålet skyldes hovedsakelig familiefaktoren. Selv etter diskontering av denne (ved divisjon med 1,5) har imidlertid Ja-svarerne en overrisiko på $10 \%$ blant menn og
14\% hos kvinner. Både sigarettantall, serumkolesterol og blodtrykk er høyere i Ja-gruppen. Også i tabellene 4 og 5 sees en lignende overrisiko for infarkt i Jagruppen. Bare når det gjelder sigaretter hos dem med høyt blodtrykk blant foreldre eller søsken, er gjennomsnittet gunstigere enn i Nei-gruppen.

Vi vet ikke om de personer som er blitt kjent med infarkt/angina eller sukkersyke eller høyt blodtrykk blant foreldre eller søsken, av den grunn har gjort noe forsøk på f.eks å redusere sin kroppsmasseindex eller sitt sigarettantall. Men dersom slike forsøk er gjort, er resultatet lite tilfredsstillende.

\section{REGISTRERING AV FAMILIEANAMNESE I ANDRE NORSKE UNDERSØKELSER}

Eksemplene ovenfor er basert på maksimalt enkle spørsmål som ignorerer omfanget av slektningenes alders- og kjønnspesifikke eksposisjon og alder og kjønn for sykdomsdiagnose. Registrering og analyse kan imidlertid gjøres vesentlig mere komplisert.

I Tromsø i 1974 (7) ble 6595 menn undersøkt. Ved undersøkelsen registrerte man alle første grads slektninger med kjønn, fødselsår, dødsår og år for opptreden av hjerteinfarkt. Infarktdiagnosene ble verifisert i journaler eller dødsårsaksregister. I alt ble nærmere 
25000 første grads slektninger registrert hvorav 993 som infarkt positive. Med disse data ble det for hver mann beregnet en risikoscore basert på mannlige og en på kvinnelige slektninger. Disse scoreverdier ble brukt som avhengige variable i multiple lineære regresjoner med blodtrykk, blodlipider etc. som uavhengige.

Tabell 3. Variabelgjennomsnitt i relasjon til hjerteinfarkt eller angina pectoris hos foreldre eller søsken. Personer som ikke selv har hatt hjerteinfarkt/angina pectoris eller brystsmerter som peker mot angina pectoris.

\begin{tabular}{|c|c|c|}
\hline $\begin{array}{l}\text { Hjerteinfarkt eller } \\
\text { a.p. hos foreldre } \\
\text { eller søsken }\end{array}$ & MENN & KVINNER \\
\hline & \multicolumn{2}{|c|}{ Antall* } \\
\hline $\mathrm{Ja}$ & 3839 & 4380 \\
\hline Nei & 6596 & 6762 \\
\hline \multirow[t]{3}{*}{ Vet ikke } & 495 & 428 \\
\hline & \multicolumn{2}{|c|}{ Gjennomsnitt } \\
\hline & \multicolumn{2}{|c|}{ Kroppsmasseindex $\left(\mathrm{g} / \mathrm{cm}^{2}\right)$} \\
\hline $\mathrm{Ja}$ & 2,55 & 2,42 \\
\hline $\mathrm{Nei}$ & 2,54 & 2,40 \\
\hline Vet ikke & 2,56 & 2,46 \\
\hline
\end{tabular}

\begin{tabular}{lcc} 
Ja & 6,9 & 5,8 \\
Nei & 6,7 & 5,2 \\
Vet ikke & 8,2 & 6,8 \\
& \multicolumn{2}{c}{ Serumkolesterol (mmol/l) } \\
& 6,09 & 5,74 \\
Ja & 5,95 & 5,59 \\
Nei & 5,96 & 5,71
\end{tabular}

Serumtriglyserider $(\mathrm{mmol} / \mathrm{l})$

\begin{tabular}{|c|c|c|}
\hline $\mathrm{Ja}$ & 2,17 & 1,32 \\
\hline Nei & 2,03 & 1,25 \\
\hline \multirow[t]{2}{*}{ Vet ikke } & 2,13 & 1,35 \\
\hline & \multicolumn{2}{|c|}{ Systolisk blodtrykk (mm) } \\
\hline $\mathrm{Ja}$ & 135,9 & 126,7 \\
\hline Nei & 135,2 & 125,1 \\
\hline \multirow[t]{2}{*}{ Vet ikke } & 135,0 & 126,3 \\
\hline & \multicolumn{2}{|c|}{ Diastolisk blodtrykk (mm) } \\
\hline $\mathrm{Ja}$ & 82,6 & 78,3 \\
\hline Nei & 81,8 & 76,9 \\
\hline \multirow[t]{2}{*}{ Vet ikke } & 82,3 & 78,4 \\
\hline & \multicolumn{2}{|c|}{$\begin{array}{l}\text { Infarktrisk (scoreenheter) } \\
\text { Geometrisk gjennomsnitt }\end{array}$} \\
\hline $\mathrm{Ja}$ & 33,7 & 4,64 \\
\hline Nei & 20,5 & 2,72 \\
\hline Vet ikke & 33,0 & 4,85 \\
\hline
\end{tabular}

* Basert på kroppsmasseindex. For de andre variable er antallene ubetydelig større eller mindre.
I fire kommuner i Finnmark i 1977 (8) ble det etablert familiegrupper blant de undersøkte - far, mor, søsken. 1377 personer i 575 familier ble inkludert i en stianalyse som "...gave evidence of significant biologic and environmental transmission for total cholesterol..., high density lipoprotein cholesterol..., triglycerides..., and systolic... and diastolic blood pressure..."

En enklere registrering ble foretatt på et tilleggsskjema i Tromsø i 1980 og i 1986-87, i Finnmark 1987-88 og i Nordland 1988-89. Det ble bedt om særskilt avkryssing av sykdom for far, mor, søsken, bror, uten registrering av eventuelt dødsår eller av antall søsken. Sykdommene har vært et varierende utvalg fra Hjerneslag, Sukkersyke, Leddgikt, Bechterew, Brystkreft, Annen kreftsykdom, Urinveissten, Psoriasis, Magesår eller tolvfingertarmssår, Astma, Epilepsi, Migrene.

Tabell 4. Variabelgjennomsnitt i relasjon til sukkersyke hos foreldre eller søsken. Personer som ikke selv har sukkersyke.

\begin{tabular}{|c|c|c|}
\hline $\begin{array}{l}\text { Sukkersyke hos } \\
\text { foreldre/søsken }\end{array}$ & MENN & KVINNER \\
\hline & \multicolumn{2}{|c|}{ Antall* } \\
\hline $\mathrm{Ja}$ & 786 & 931 \\
\hline \multirow[t]{3}{*}{ Nei } & 6017 & 6699 \\
\hline & \multicolumn{2}{|c|}{ Gjennomsnitt } \\
\hline & \multicolumn{2}{|c|}{ Kroppsmasseindex $\left(\mathrm{g} / \mathrm{cm}^{2}\right)$} \\
\hline $\mathrm{Ja}$ & 2,61 & 2,48 \\
\hline \multirow[t]{2}{*}{ Nei } & 2,53 & 2,40 \\
\hline & \multicolumn{2}{|c|}{ Antall sigaretter pr. dag pr. skjemasvare } \\
\hline $\mathrm{Ja}$ & 6,6 & 5,6 \\
\hline \multirow[t]{2}{*}{ Nei } & 6,5 & 5,1 \\
\hline & \multicolumn{2}{|c|}{ Serumkolesterol (mmol/l) } \\
\hline $\mathrm{Ja}$ & 6,05 & 5,75 \\
\hline \multirow[t]{2}{*}{ Nei } & 6,00 & 5,65 \\
\hline & \multicolumn{2}{|c|}{ Serumtriglyserider $(\mathrm{mmol} / \mathrm{l})$} \\
\hline $\mathrm{Ja}$ & 2,25 & 1,42 \\
\hline \multirow[t]{2}{*}{ Nei } & 2,06 & 1,25 \\
\hline & \multicolumn{2}{|c|}{ Systolisk blodtrykk (mm) } \\
\hline $\mathrm{Ja}$ & 135,7 & 127,2 \\
\hline \multirow[t]{2}{*}{ Nei } & 135,1 & 125,5 \\
\hline & \multicolumn{2}{|c|}{ Diastolisk blodtrykk (mm) } \\
\hline $\mathrm{Ja}$ & 82,2 & 78,4 \\
\hline \multirow[t]{2}{*}{ Nei } & 81,8 & 77,2 \\
\hline & \multicolumn{2}{|c|}{$\begin{array}{l}\text { Infarktrisk (scoreenheter) } \\
\text { Geometrisk gjennomsnitt }\end{array}$} \\
\hline $\mathrm{Ja}$ & 26,7 & 3,81 \\
\hline Nei & 24,0 & 3,26 \\
\hline
\end{tabular}

* Basert på kroppsmasseindex. For de andre variable er antallene ubetydelig større eller mindre. 
I Sør-Varanger 1994 ble det spurt om Astma, "Høysnue", Eksem, Elveblest, Annen allergi særskilt for mor, far, søsken, barn og andre.

I Nord-Trøndelag 1995-97 ber tilleggsskjemaet om særskilt avkryssing for mor, far, bror, søster, barn av bl.a. Hjerteinfarkt før 60 års alder, Høyt blodtrykk, Diabetes med alder ved start, Psykiske plager og Osteoporose. De fleste av disse spørsmål var også med i Tromsø 1994-95.

Mere omfattende var spørsmålene på tilleggsskjemaet i Hordaland 1992-93. Det ble spurt om far og mor var i live, eventuelt dødsår og dødsårsak, videre om antall brødre og søstre og om alle søsken var i live. Sykdomslisten for familien inkluderte bl.a. Blodpropp i legg/lår, Årebetennelse, Nyresykdom, Leversykdom, Lungekreft, Magekreft, Tykktarmskreft, Kreft i prostata, Brystkreft, Annen kreft.

\section{KOMMENTAR}

Til tross for at bias aldri helt kan utelukkes, selv i prospektive dødelighetsanalyser, synes det rimelig å registrere opplysninger om blodsslektninger i epidemiologiske undersøkelser av kroniske sykdommer. Data som allerede er innsamlet fra de mange norske undersøkelser, vil trolig være verd å analysere. Det vil være en fordel med samordning, kanskje i mange tilfeller en sammenslåing. Spesielt gjelder dette koblinger til dødsårsaks- eller uførepensjonsregister, der telleren vil bli liten for den enkelte undersøkelse.
Tabell 5. Variabelgjennomsnitt i relasjon til høyt blodtrykk hos foreldre eller søsken. Personer som ikke selv står på medikamentell blodtrykksbehandling.

\begin{tabular}{|c|c|c|}
\hline \multirow[t]{2}{*}{$\begin{array}{l}\text { Høyt blodtrykk } \\
\text { hos foreldre/søsken }\end{array}$} & MENN & KVINNER \\
\hline & \multicolumn{2}{|c|}{ Antall* } \\
\hline $\mathrm{Ja}$ & 2240 & 3279 \\
\hline \multirow[t]{3}{*}{ Nei } & 5279 & 5111 \\
\hline & \multicolumn{2}{|c|}{ Gjennomsnitt } \\
\hline & \multicolumn{2}{|c|}{ Kroppsmasseindex $\left(\mathrm{g} / \mathrm{cm}^{2}\right.$} \\
\hline $\mathrm{Ja}$ & 2,56 & 2,42 \\
\hline \multirow[t]{2}{*}{ Nei } & 2,52 & 2,39 \\
\hline & \multicolumn{2}{|c|}{ Antall sigaretter pr. dag pr. skjemasvar } \\
\hline $\mathrm{Ja}$ & 6,1 & 5,0 \\
\hline \multirow[t]{2}{*}{ Nei } & 6,7 & 5,3 \\
\hline & \multicolumn{2}{|c|}{ Serumkolesterol $(\mathrm{mmol} / \mathrm{l})$} \\
\hline $\mathrm{Ja}$ & 6,01 & 5,68 \\
\hline \multirow[t]{2}{*}{ Nei } & 6,00 & 5,64 \\
\hline & \multicolumn{2}{|c|}{ Serumtriglyserider $(\mathrm{mmol} / \mathrm{l})$} \\
\hline $\mathrm{Ja}$ & 2,16 & 1,26 \\
\hline \multirow[t]{2}{*}{ Nei } & 2,04 & 1,25 \\
\hline & \multicolumn{2}{|c|}{ Systolisk blodtrykk (mm) } \\
\hline $\mathrm{Ja}$ & 137,6 & 127,9 \\
\hline \multirow[t]{2}{*}{ Nei } & 134,0 & 124,1 \\
\hline & \multicolumn{2}{|c|}{ Diastolisk blodtrykk (mm) } \\
\hline \multirow{3}{*}{$\begin{array}{l}\mathrm{Ja} \\
\mathrm{Nei}\end{array}$} & 83,7 & 78,9 \\
\hline & 81,0 & 76,1 \\
\hline & \multicolumn{2}{|c|}{$\begin{array}{l}\text { Infarktrisk (scoreenheter) } \\
\text { Geometrisk gjennomsnitt }\end{array}$} \\
\hline $\mathrm{Ja}$ & 26,2 & 3,56 \\
\hline Nei & 23,4 & 3,13 \\
\hline
\end{tabular}

\section{REFERANSER}

1. Bjartveit K, et al. The Cardiovascular Disease Study in Norwegian Counties. Results from First Screening. Acta Med Scand 1983 (Suppl 675).

2. National Health Screening Service, et al. The cardiovascular disease survey in Nord-Trøndelag 1989. Statens helseundersøkelser, Oslo 1991.

3. National Health Screening Service, et al. The cardiovascular disease study in Norwegian counties. Results from second screening. Statens helseundersøkelser, Oslo 1988.

4. Tverdal A. A mortality follow-up of persons invited to a cardiovascular disease study in five areas in Norway. Statens helseundersøkelser, Oslo 1989.

5. Statens helseundersøkelser, et al. Helseundersøkelsene i Østfold 1985 og 1988 og Aust-Agder 1986 og 1989. Statens helseundersøkelser, Oslo 1997.

6. Statens helseundersøkelser. Håndbok for hjerte-kar-undersøkelsen. 40-åringsprosjektet. Oslo 1987.

7. Thelle DS, Førde OH, Arnesen E. The Tromsø Heart Study: A model for describing family-associated risk for coronary heart disease as a continuous variable. ISM skriftserie Nr. 4, Tromsø 1979.

8. Brenn T. Genetic and environmental effects on coronary heart disease risk factors in Northern Norway. The cardiovascular disease study in Finnmark. Ann Hum Genet 1994; 58: 369-79. 